REF - ISSก 1888-8884 Vol. IV [2], 159-168, 28日7

\title{
EFEITO DO LASER As-Ga-AI DE BAIXA POTÊNCIA SOBRE O MÚSCULO GASTROCNÊMIO DE RATO SUBMETIDO À LESÃO MECÂNICA
}

\section{Low-power As-Ga-Al laser effect on the gastrocnemius muscle of rats submitted to mechanic lesioning}

\author{
Marcelo M. M. Luz ${ }^{1}$, Fernanda G. R. Luz ${ }^{1}$, Maria de F. R. Silva², Cláudia S.Oliveira ${ }^{3}$, \\ Fabiana R. da Mata ${ }^{4}$, João R. da Mata ${ }^{4}$. \\ ${ }^{1}$ Faculdade UNISAÚDE de Goiânia - Av. Dr. Irani Alves Ferreira, 220 \\ Setor Aeroporto - CEP: 74.075-290 - Goiânia - Goiás. \\ ${ }^{2}$ Universidade de Rio Verde - FESURVE - Fazenda Fontes do Saber - s/n - Caixa Postal Rio Verde - CEP: \\ 75.901-970- Rio Verde - Goiás. \\ ${ }^{3}$ Universidade do Vale do Paraíba-UNIVAP-Av. Shishima Hifumi, 2911 - Urbanova \\ 12.244-000 - São José dos Campos - São Paulo. \\ ${ }^{4}$ Universidade Federal de Goiás,_Câmpus Samambaia (Câmpus II) - ICB-III - DMORF - CEP:74001-970 - Caixa \\ Postal: 131 - Goiânia - Goiás
}

Autor para correspondência: irdamata@pop.com.br

Recebido em 18/09/2007 - Aceito em 28/11/2007

\begin{abstract}
RESUMO: O músculo é um tecido biológico portador de plasticidade, com alto grau de remodelamento frente a diversos estímulos. Também é frequentemente afetado por traumas da vida diária e atividades de esportes. Assim a rápida recuperação deste tecido com manutenção de suas propriedades mecânicas é importante para o indivíduo. Vários estudos indicam a eficiência do laser para a modulação da resposta inflamatória em tecidos de pele, tendões, músculos e ossos. O objetivo deste trabalho foi avaliar os efeitos da radiação do laser As-Ga-Al, na reparação do músculo gastrocnêmio de ratos após trauma mecânico. Foram utilizados 48 ratos da linhagem Wistar sacrificados metade destes aos oito dias e o restante aos 15 dias após o início do experimento. Os animais foram separados nos seguintes grupos contendo oito animais cada um: dois grupos controles, dois grupos apenas lesados e dois grupos lesados e tratados. Os músculos gastrocnêmios dos grupos de animais lesados foram submetidos a um trauma, através de impacto por um aparelho promotor de trauma mecânico. Os grupos lesados e tratados receberam irradiação de laser com $10 \mathrm{~J} / \mathrm{cm}^{2}$ no $1^{2}, 3^{2}, 5^{2}$ e $7^{\circ}$ dias após a lesão. Os grupos apenas lesados não foram irradiados, mas submetidos aos mesmos procedimentos, porém com aparelho de laser As-GaAl desligado. No dia do sacrifício, os animais foram anestesiados com Rompum $^{\circledR}$ e Ketalar $^{\circledR}$ em doses de 0.10 $\mathrm{ml} / 100 \mathrm{~g}$ de massa corporal e decapitados. Os músculos gastrocnêmios foram retirados, fixados em formol a $10 \%$, processados, incluídos em parafina, seccionados e corados com hematoxilina/eosina. Algumas lâminas foram coradas por picrosirius red e fast green para observação de colágeno. Não houve alterações no processo inflamatório, quanto ao número de polimorfonucleares, fibroblastos, macrófagos e monócitos em relação aos grupos controles. As análises histomorfométricas, demonstraram melhora na distribuição do tecido colágeno nos grupos lesados e tratados e diminuição de colágeno nos animais lesados e tratados com sacrifício aos 15 dias. Deste modo, a laserterapia nos moldes utilizados neste experimento, pode ser útil no tratamento das lesões musculares por promover diminuição de colágeno na fase mais tardia da reparação tecidual, com rearranjo mais adequado deste tecido. Este recurso terapêutico previne retrações musculares e excesso de colágeno, propiciando recuperação mais adequada e precoce da atividade muscular.
\end{abstract}

PALAVRAS CHAVES: Sistema músculo-esquelético, Colágeno, Lasers. 


\begin{abstract}
The muscle is a biological tissue that possesses plasticity, and presents a high degree of remodeling facing several stimulations. It is also frequently affected by normal-life and sports-related traumas. In this manner, this tissue's fast recovery, maintaining its mechanic properties is of extreme importance to the individual. Several studies indicate the laser's efficiency regarding the modulation of the inflammatory response in skin, tendon, muscle and bone tissues. The objective of this work was to evaluate the effects the As-Ga-Al laser radiation has regarding the reparation of the gastrocnemius muscle of rats after a mechanic trauma. Forty-eight rats from the Wistar lineage were utilized, from which half were sacrificed at eight days and the remaining half at 15 days from the beginning of the experiment. The animals were separated into the following groups, each containing eight animals each: two control groups, two only lesioned groups and two lesioned and treated groups. The gastrocnemius muscles of the lesioned group animals were submitted to a trauma, through an impact caused by a mechanic trauma-inducing device. The lesioned and treated group animals received laser irradiation with $10 \mathrm{~J} / \mathrm{cm}^{2}$ at day 1, 3, 5, and 7 following the lesioning. The lesioned group animals were not irradiated, but submitted to the same procedures, only with the As-Ga-Al laser device turned off. At the day of the sacrifice, the animals were given anesthetics (Rompum ${ }^{\circledR}$ and Ketalar ${ }^{\circledR}$ ) using a dosage of $0,10 \mathrm{~mL} / 100 \mathrm{~g}$ of bodily mass, and were then decapitated. The gastrocnemius muscles were retrieved, fixated in formaldehyde at $10 \%$, processed, included in paraffin, sectioned and colored with hematoxillin/eosin. Some of the slides were colored with picrosirius red and fast green in order to observe the collagen. There were no alterations in the inflammatory process regarding the number of polymorph nuclear cells, fibroblasts, macrophages and monocytes, in comparison to the control groups. The histomorphometric assessment analysis demonstrated an improvement in the collagen tissue distribution in the lesioned and treated groups and a decrease in collagen levels in the lesioned and treated groups that suffered sacrifice at 15 days. Thus, laser therapy in the models utilized in this experiment may be useful in the treatment of muscular lesions, for it promotes a decrease in collagen during the latest stage of tissue reparation, therefore inducing a more adequate rearranging of this tissue. This therapeutic resource prevents the excess of collagen and also muscular retractions, making way for a more adequate and precocious recovery of muscular activity.
\end{abstract}

KEYWORDS: Musculoskeletal System, Collagen, Lasers.

\title{
INTRODUÇÃO
}

O laser (Lingt Amplification by Stimulated Emission of Radiation) foi idealizado em 1917 (VEÇOSO, 1993; BRUGNERA \& PINHEIRO, 1998) e utilizado como recurso terapêutico a partir de 1965 (COLLS, 1988; SCHINDL et al, 2000; PEREIRA et al, 2002). O laser acelera a transcrição e replicação do DNA (ácido desoxirribonucléico), a produção de ATP (adenosina trifosfato), a atividade mitocondrial, a cicatrização tecidual e a angiogênese (KARU et al, 1995; REDDY et al, 1998; BEN-DOV et al, 1999; SCHINDL et al, 2000; SHEFER et al, 2002; SHEFER et al, 2003). O laser tem efeito bioestimulante muscular (ANDERS et al, 1993; LAAKSO et al, 1993; SOTELO et al, 1996; SCHINDL et al, 2000; MATAMALA et al, 2001; GUIRRO \& GUIRRO, 2002) e induz liberação de substancias pré-formadas, como histaminas, serotonina e bradicinina, além de promover estimulação ou inibição de reações enzimáticas (SCHINDL et al, 2000). O laser ainda apresenta ação antiinflamatória, analgésica, estimulante celular e modulador do tecido conjuntivo na regeneração e na cicatrização do tecido muscular (STAINKI et al, 1998).

A ação analgésica ocorre dentre outros fatores, devido à redução da inflamação pela reabsorção de exsudatos, pela estimulação da microcirculação, alteração no metabolismo das serotoninas (FREITAS \& BARANAUSKAS 2000; SCHINDL et al, 2000). O efeito antiinflamatório é devido à interferência na síntese de prostaglandinas e a ação microcirculatória o que favorece o tecido lesionado propiciando células de defesa e adequada oxigenação (COTRAN \& ROBBINS 2000; FREITAS \& BARANAUSKAS 2000). O laser atua na fase proliferativa do processo inflamatório, estimulando os efeitos regenerativos e ainda leva ao rearranjo estrutural do citoesqueleto e a modulação celular (MEDRADO et al, 2003). O efeito antiedematoso é intensificado pela ativação da microcirculação (COTRAN \& ROBBINS, 2000).

O laser aplicado nas primeiras horas após a lesão, otimiza a cicatrização e regeneração muscular pelo aumento da mobilidade mioblástica e de miofribrilas jovens com proliferação de células satélites e neoformação de vasos sanguíneos na área irradiada. (BEN-DOV et al, 1999; AMARAL et al, 2001, BULYAKOVA et al, 2002; SHEFER et al, 2002; SHEFER et al, 2003).

O laser composto por Arsenieto de Gálio e Alumínio (As-Ga-Al) tem demonstrado intensos efeitos sobre tecidos biológicos. No processo de cicatrização acelera a reparação tecidual pela diminuição do edema, melhoria no tecido de granulação, e estimulação da proliferação de fibroblastos com deposição organizada de colágeno (MEDRADO et al, 2003; PUGLIESE et al, 2003).

Este trabalho teve como objetivo avaliar os efeitos da terapia do laser Arsenieto de Gálio e Alumínio sobre o músculo gastrocnêmio de ratos submetidos à lesão por trauma mecânico. 


\section{MATERIAL E MÉTODO}

Foram utilizados 48 ratos (Rattus norvergicus), machos da linhagem WISTAR, de 70 dias de idade. Os animais permaneceram no Laboratório de Experimentação Animal, da Universidade Federal de Uberlândia, a temperatura de $25^{\circ} \mathrm{C}$, umidade $40 \%$, luminosidade dia/ noite de 12 horas e receberam ração Nuvilab e água a vontade durante todo o experimento. Os animais foram divididos em seis grupos de 8 animais cada um.

Grupos com sacrifícios aos 8 dias após a lesão.

Grupo $1 \mathrm{~A}$ - Controle (não lesados)

Grupo 2A - Apenas lesado

Grupo 3A - Lesado e tratado com laser

Grupos com sacrifícios aos 15 dias após a lesão.

Grupo 4A - Controle (não lesados)

Grupo 5A - Apenas lesado

Grupo 6A - Lesado e tratado com laser

Os animais foram anestesiados com quetamina a $5 \%$ e xilasina a $2 \%$ na proporção de $1: 4$ em dose de 0,10 a $0,15 \mathrm{ml} / 100 \mathrm{~g}$ de massa corporal, foi feita a seguir a lesão na perna direita utilizando o equipamento Promotor de Trauma Mecânico (FILHO-FRIETAS et al, 2006) através do impacto de um pino de ferro com massa de $320 \mathrm{~g}$ solta de uma altura de $21 \mathrm{~cm}$.

A irradiação do laser foi realizada pelo equipamento Laser Physiolux Dual da Bioset de geração de onda de 2000 Hertz, de comprimento de onda de 785 nm - Arsenieto de Gálio e Alumínio (Fig. 1A).
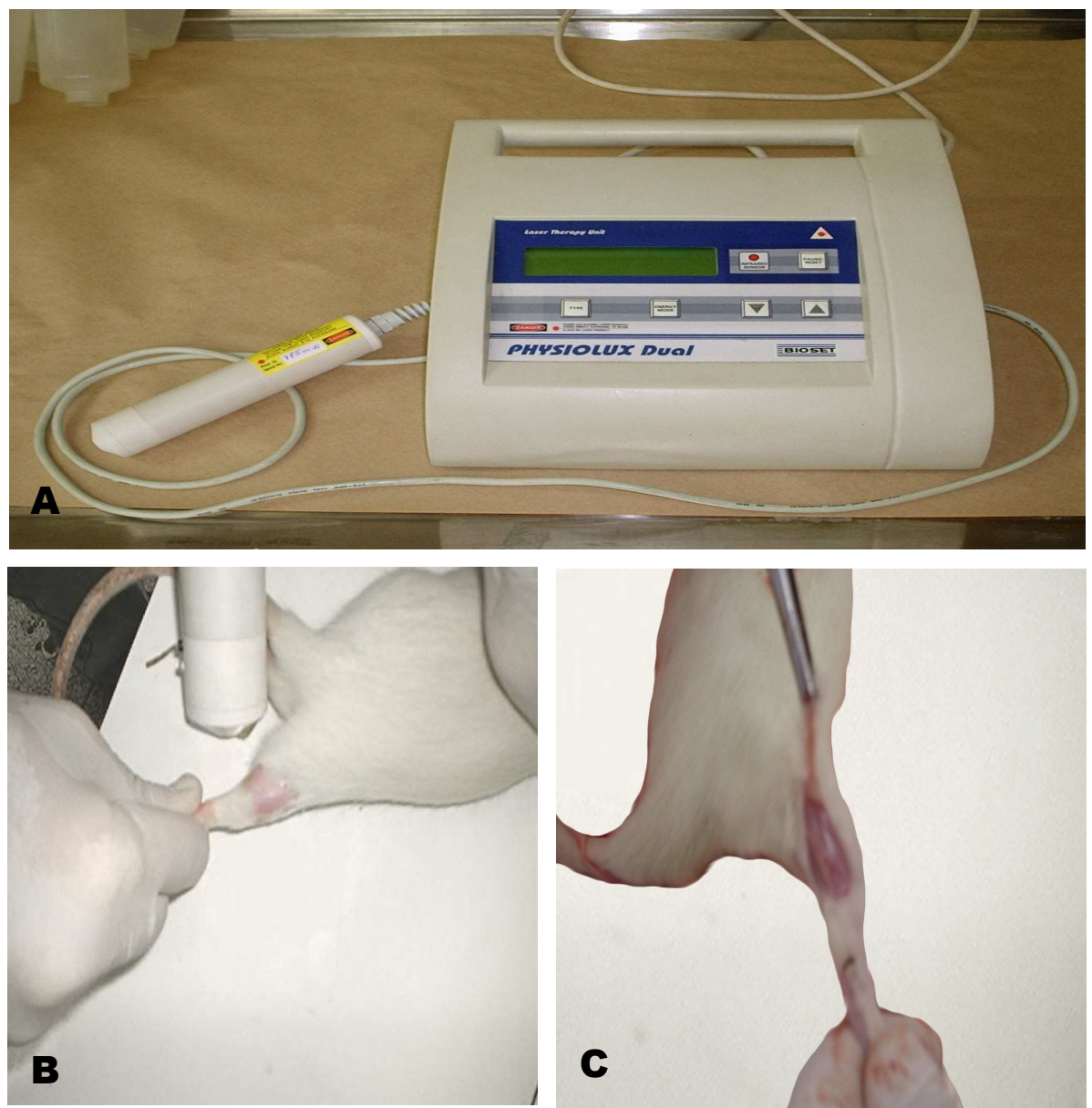

Figura 1A. Equipamento Laser Physiolux Dual da Bioset-As-Ga-Al de 785 nm.

Figura 1B. Técnica de aplicação do laser As-Ga-Al 785 nm sobre o músculo gastrocnêmio.

Figura 1C. Técnica cirúrgica para retirada do músculo gastrocnêmio. 
A aplicação do laser As-Ga-Al foi iniciada no primeiro dia, 2 horas após lesão, pelo método transcutâneo em apenas um ponto, com dose de $10 \mathrm{~J} / \mathrm{cm}^{2}$. Os animais foram posicionados sobre uma plataforma, em decúbito ventral com hiperextensão do membro inferior direito. A aplicação do laser foi realizada no $1^{\circ}, 3^{\circ}, 5^{\circ}$ e $7^{\circ}$ dia após lesão. A incidência foi realizada diretamente na pele da região lesionada, com o contato direto da caneta sobre esta região em ângulo de $90^{\circ}$ (Fig. 1B). Os animais controle também receberam o mesmo tipo de manipulação que os animais irradiados, porém com o laser desligado.

Ao final da fase experimental, os animais foram submetidos à anestesia utilizando injeção intraperitoneal de Rompum $^{\circledR}$ e Ketalar $^{\circledR}$ em doses iguais de $0.10 \mathrm{ml}$ de solução para cada $100 \mathrm{~g}$ de massa corporal e o sacrifício dos animais foi realizado por decapitação. Os músculos gastrocnêmios foram retirados através de técnica cirúrgica (Fig. 1C).

Os músculos gastrocnêmios foram fixados em formol a $10 \%$ durante 48 horas. O material foi processado para técnica histológica clássica, incluído em parafina, seccionado, montado em lâmina e corada por hematoxilina/eosina.

Para observação do colágeno algumas lâminas foram coradas por picrosirius red e fast green. As lâminas foram imersas em solução de ácido fosfomolibidênico $0,2 \%$, e a seguir no picrosirius red, enxaguadas em solução $0,01 \mathrm{NHCl}$ e em etanol e Xilol e montadas. O material foi fotografado em microscópio Olympus Triocular BX40, acoplado a câmera Oly-200 ligada a um computador através de placa digitalizadora (Data Translation 3153). Para a análise estatística utilizou-se o teste t-Student com nível de significância de $5 \%(p<0,05)$.

\section{RESULTADOS E DISCUSSÃO}

No oitavo dia após a lesão estiveram presentes no processo inflamatório, células gigantes, fibroblastos, macrófagos, monócitos, linfócitos e neovascularização tanto no grupo lesado e tratado quanto no apenas lesado. Não houve diferenças significativas no número de células e na neovascularização entre os grupos lesado e tratado e o apenas lesado (Fig. 2).

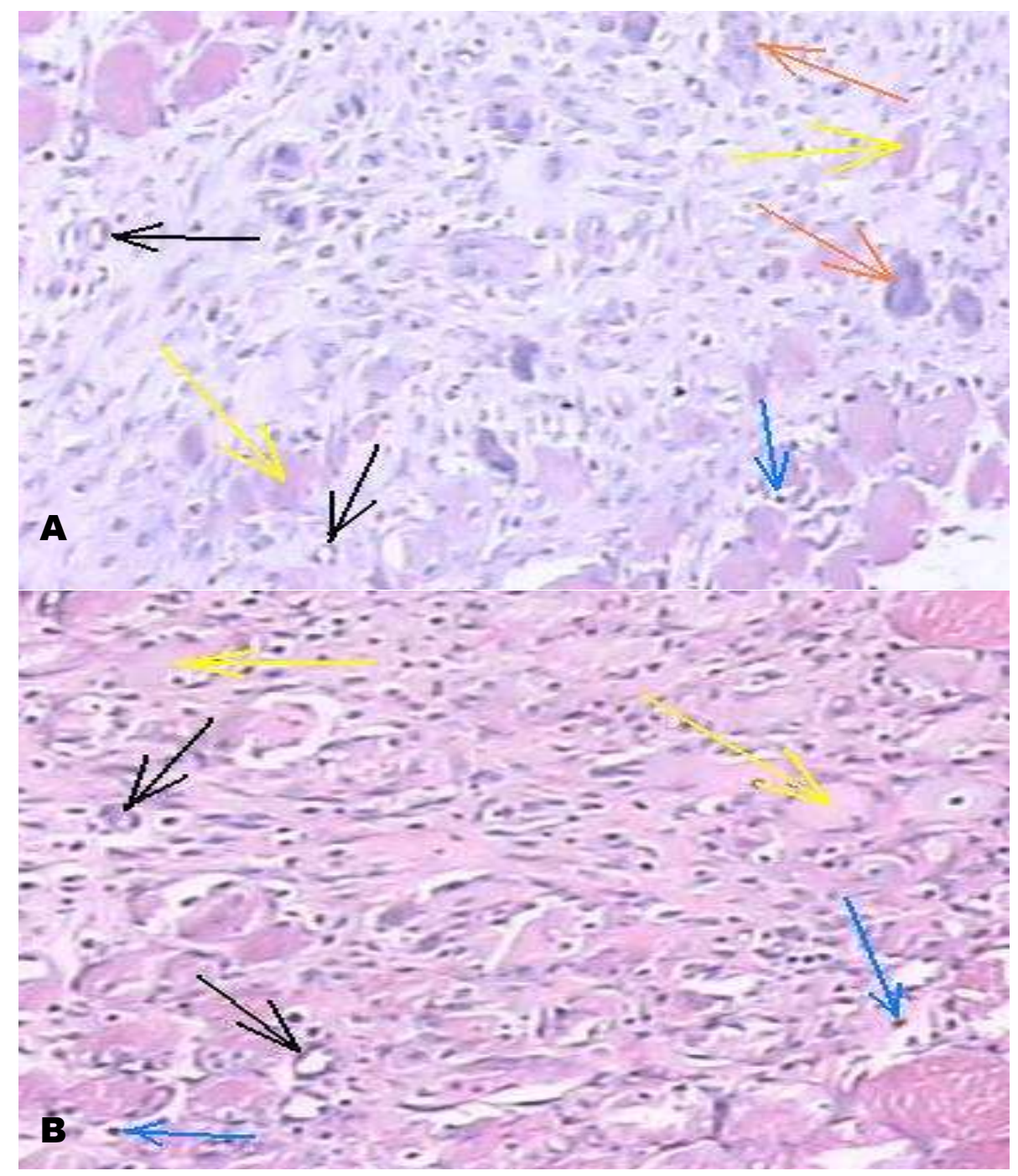


Figura 2. Músculo gastrocnêmio de ratos aos 8 dias após lesão mecânica, corado com hematoxilina e eosina, 300X. A - grupo apenas lesado; B - grupo lesado e tratado. Células mononucleadas(setas azuis); células gigantes(setas alaranjadas); fibra muscular(setas amarelas); neovascularização(setas pretas).

Após 15 dias de lesão muscular, também estiveram presente células relacionadas ao processo inflamatório e neovascularização, sem diferenças significativas do número de células entre os grupos lesados e tratados e o apenas lesado (Fig. 3). Não houve diferença significativa, no número de células do processo inflamatório e na neovascularizacão, entre os grupos sacrificados aos 8 e aos 15 dias após a lesão, tanto nos animais do grupo lesado e tratado, quanto no apenas lesado.
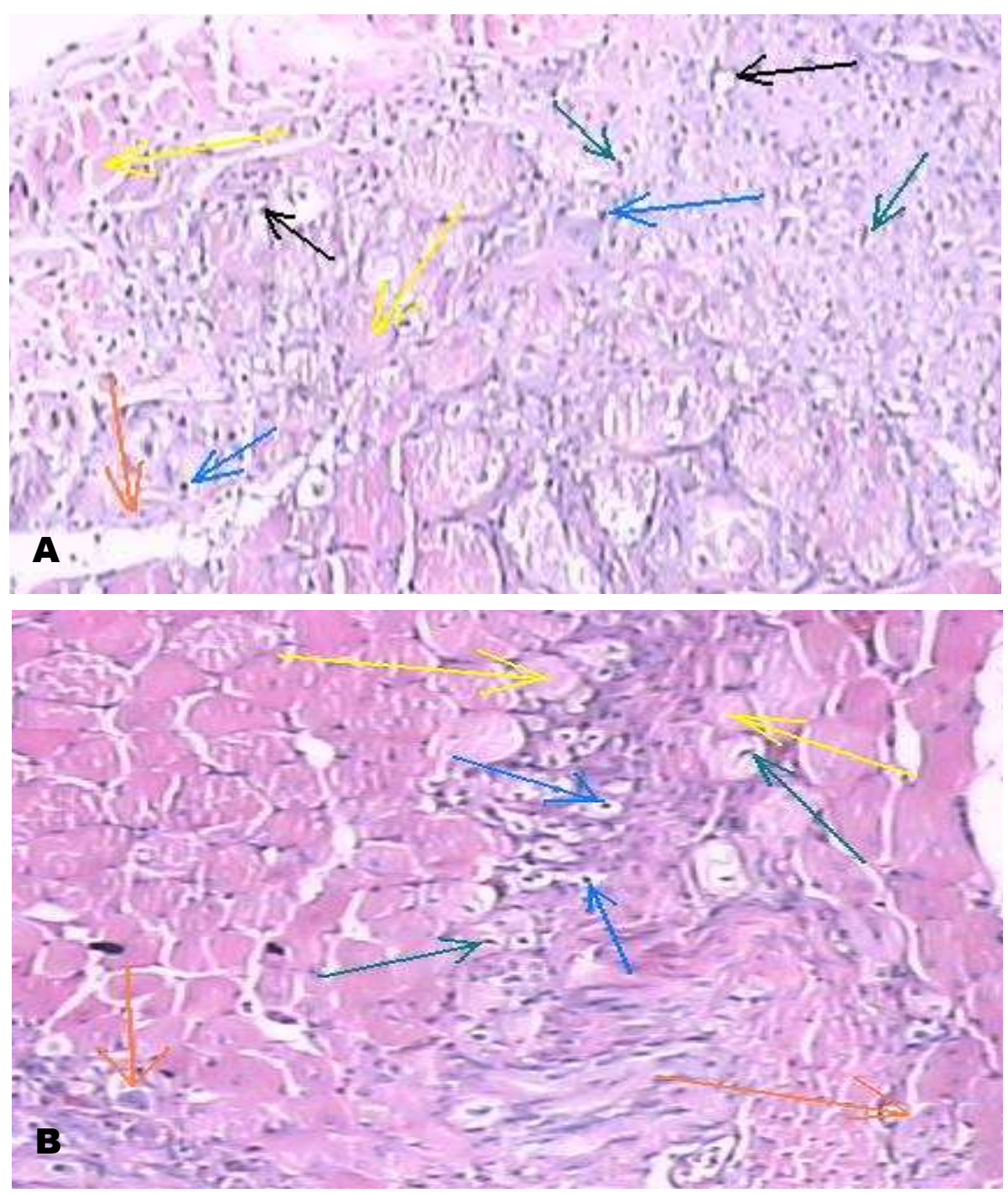

Figura 3. Músculo gastrocnêmio de ratos aos 15 dias após lesão mecânica, corado com hematoxilina e eosina, 300X. A - grupo apenas lesado; B - grupo lesado e tratado. Células mononucleadas(setas azuis); células gigantes(setas alaranjadas); fibra muscular(setas amarelas); neovascularização(setas pretas).

A distribuição do colágeno e das fibras musculares no oitavo dia após a lesão, demonstrou fibras musculares com diâmetro maiores e fibras colágenas com distribuição bastante uniforme entre estas, no grupo lesado e tratado. O grupo apenas lesado apresentou fibras musculares de diâmetros menores, e áreas com predominância de concentração de colágeno em relação a fibras musculares (Fig. 4). 


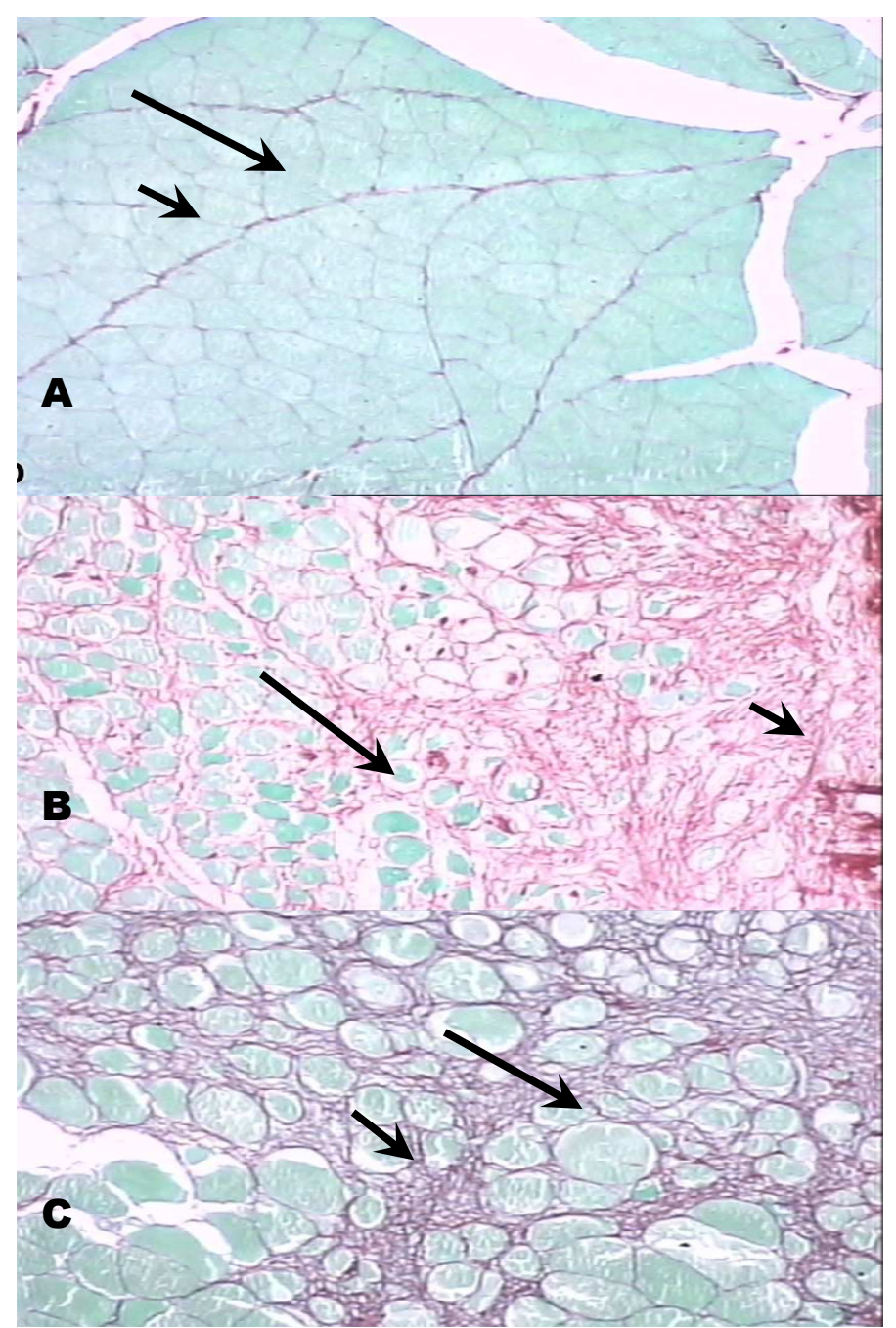

Figura 4. Músculo gastrocnêmio de ratos aos 8 dias após lesão mecânica corado com sirus red e fast green, $300 X$.

A - grupo controle. Fibra colágena (seta menor); fibra muscular (seta maior).

B - grupo apenas lesado. Fibra colágena (seta menor); fibra muscular (seta maior).

C - grupo lesado e tratado. Fibra colágena (seta menor); fibra muscular (seta maior).

Aos 15 dias após a lesão, o grupo de animais lesado e tratado apresentou pouco colágeno, porém com boa distribuição entre as fibras musculares enquanto o grupo apenas lesado demonstrou muitas fibras colágenas, porém mais isoladas em relação às fibras musculares (Fig. 5). 

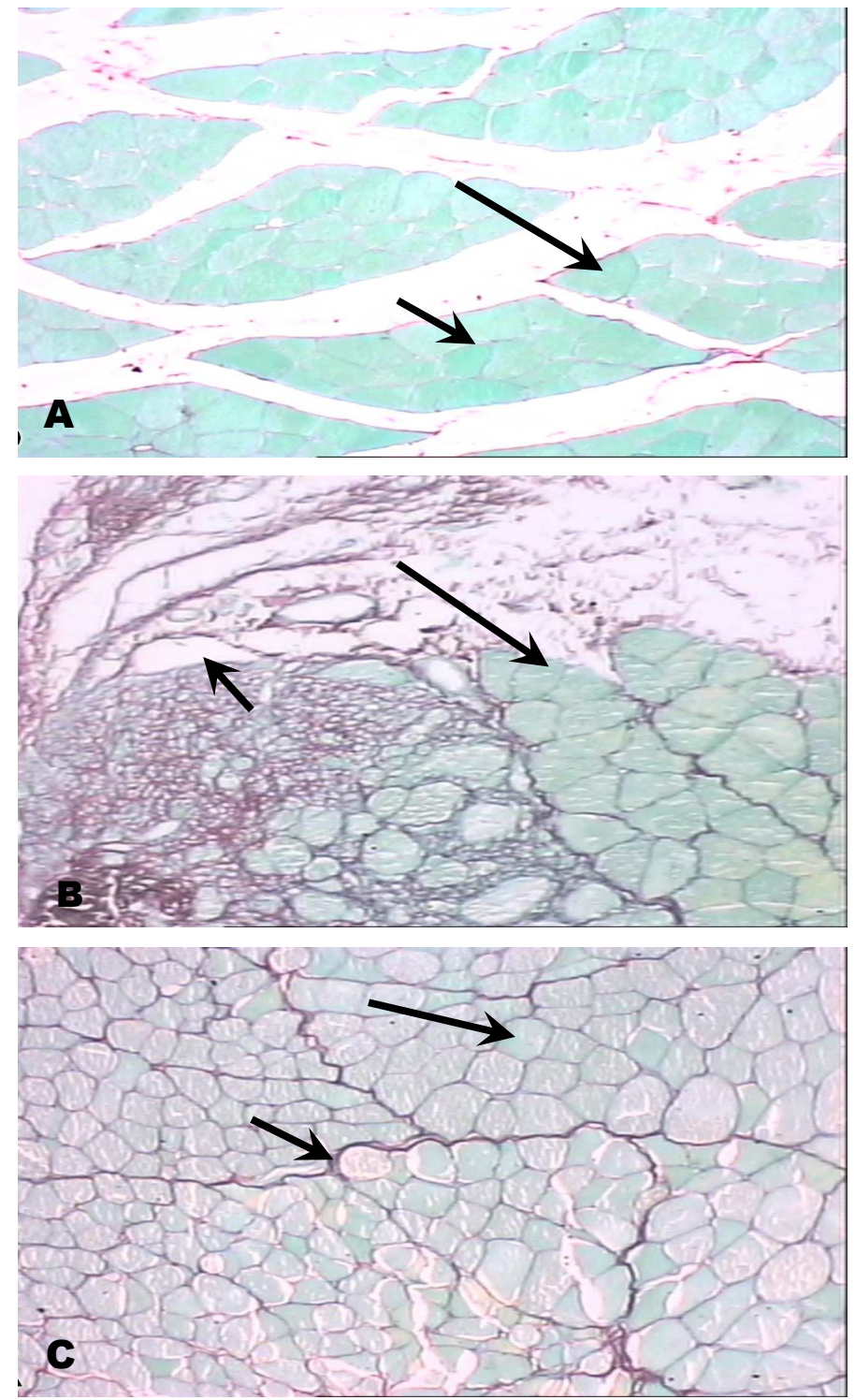

Figura 5. Músculo gastrocnêmio de ratos aos 15 dias após lesão mecânica, corado com sirus red e fast green, $300 X$.

A - grupo controle. Fibra colágena (seta menor); fibra muscular (seta maior).

B - grupo apenas lesado. Fibra colágena (seta menor); fibra muscular (seta maior).

C - grupo lesado e tratado. Fibra colágena (seta menor); fibra muscular (seta maior).

Para os animais com sacrifícios no $8^{\circ}$ dia após a lesão, a quantidade de colágeno foi maior no grupo lesado e tratado do que no grupo apenas lesado. Todavia, aos 15 dias após a lesão houve diminuição na quantidade de colágeno (Tab. 1), porém com melhor distribuição no grupo lesado e tratado em relação ao grupo apenas lesado.

Tabela 1. Valores percentuais histomorfométricos médios \pm desvio padrão da quantidade de colágeno, presente no músculo gastrocnêmio de ratos, lesado mecanicamente com ou sem tratamento por laser. Os animais foram sacrificados aos 8 e 15 dias após a lesão.

Grupos

$8^{\circ}$ dia

Controle

Apenas lesado

Lesado e tratado
$5,01 \pm 1,52^{a}$

$23,03 \pm 7,92^{b}$

$36,17 \pm 5,85^{c}$
Dais do sacrifício

$15^{\circ}$ dia

$5,62 \pm 2,20^{\mathrm{a}}$

$34,87 \pm 14,09^{d}$

$15,75 \pm 7,05^{\mathrm{e}}$ 
Os valores em cada linha ou coluna com letras distintas apresentam diferenças significativas. Teste t-Student $(p<0,05)$.

A avaliação do efeito de uma ação fisioterápica experimental sobre uma lesão, prescinde de um adequado modelo de indução desta lesão. Para a indução de lesão muscular tem sido utilizado miotoxina ou cirurgias (MINAMOTO, 1999; NICOLAU, 2001; ABOU HALA, 2003), os quais apresentam o inconveniente da resposta inflamatória advinda da toxicidade da droga utilizada ou induzida pelo próprio ato cirúrgico. Assim, este trabalho utilizou a técnica de lesão por impacto mecânico (FILHO-FREITAS et al, 2006), se assemelhando o mais possível da realidade, dos constantes traumas ocorrido em desportistas ou em conseqüência da vida diária. Este método demonstrou-se bastante adequado por não ser invasivo e reproduzível com alto grau de homogeneidade.

O comprimento de onda com maior potencial para atravessar o tecido epitelial é de 750 a $800 \mathrm{~nm}$ (KARU, 2003). A irradiação com comprimento de $785 \mathrm{~nm}$ do laser As-Ga-Al usada neste experimento, permitiu efetiva ação sobre o tecido muscular subepitelial conforme verificado nos animais tratado com o laser.

A aplicação da terapia a laser, pode induzir tanto estimulação quanto inibição da formação de fibras musculares ou fibras colágenas. Este comportamento da laserterapia é dependente do tipo de laser, comprimento de onda, número de aplicações, distância da caneta ao tecido estimulado e da intensidade da irradiação utilizada (KARU et al, 1995; FISCHER et al, 2000; SCHIND et al, 2000; AMARAL et al, 2001; PEREIRA et al, 2002). Apresentam caráter estimulatório doses abaixo de $8 \mathrm{~J} / \mathrm{cm}^{2}$ e inibitório doses acima de $8 \mathrm{~J} / \mathrm{cm}^{2}$ (VICENZO et al. 2001). A irradiação de $4 \mathrm{~J} / \mathrm{cm}^{2}$ em lesão por trauma mecânica sobre tecido muscular de ratos, de fato, induziu aumento na concentração de colágeno (FILHO-FREITAS et al, 2006). Já a dose de $10 \mathrm{~J} / \mathrm{cm}^{2}$ utilizada neste experimento induziu aumento do tecido colágeno nos animais sacrificados aos 8 dias após a lesão, e diminuição nos animais sacrificados aos 15 dias. Este fato é interessante já que contribui na fase mais tardia da reparação da lesão amenizando as retrações musculares advindas do excesso de fibras colágenas (FISCHER et al, 2000)

A contagem de fibroblastos não mostrou alteração no número destas células, entre os grupos lesado e tratado e o apenas lesado sugerindo que o aumento foi devido a incremento na síntese de colágeno o que coincide com relatos de ativação celular pela irradiação do laser (SHEFER et al, 2003).

A disposição mais uniforme do colágeno no oitavo dia da lesão foi também, acompanhado por aumento do diâmetro das fibras musculares indicando incremento na reparação da lesão. Estes dados assemelham aos relatos de que o laser As-Ga-Al acelera o processo de cicatrização, abrevia a fase de exudação e reparação, diminui o edema e o tecido de granulação nas lesões e propicia a deposição organizada do colágeno (MEDRADO et al, 2003;).

O laser As-Ga-Al, utilizado em lesão muscular por miotoxina, não determinou alterações no número de células relacionadas ao processo inflamatório (PUGLIESE et al, 2003). Estes dados coincidem com a ausência de alteração na população celular verificada neste trabalho.

Como já está estabelecido, a organização do tecido colágeno no músculo lesionado é indispensável para a adequada funcionalidade deste tecido, já que o excesso e a desorganização são promotores de barreiras mecânicas inibitórias da função e regeneração muscular (FISCHER et al, 2000). Portanto, o laser na metodologia utilizada neste experimento, promoveu melhora no rearranjo e distribuição do colágeno entre as fibras musculares otimizando a recuperação da função muscular.

\section{CONCLUSÔES}

A terapia a laser de baixa potência com o laser As-Ga-Al, nos moldes utilizados e aplicado logo após a lesão seguida de quatro aplicações em dias alternados, não alterou a resposta inflamatória do tecido lesado, mas determinou melhor distribuição do colágeno entre as fibras musculares, contribuindo para prevenir quadros de retrações musculares e promovendo recuperação mais adequada e precoce da atividade muscular. Deste modo os dados indicam como ação positiva o uso deste recurso terapêutico nas lesões musculares.

\section{REFERÊNCIAS BIBLIOGRÁFICAS}

ABOU HALA, A. Z. Efeito da Irradiação Laser e da Irradiação Infravermelha em Músculo Tibial Anterior de Rato Submetido ao Processo de Fadiga Muscular. 2003. 58p.. Dissertação (Mestrado). UNIVAP - Universidade do Vale Paraíba. São Jose dos Campos - SP.

AMARAL, A. C.; PARIZOTTO, N. A.; SALVINI, T. F. Dose-dependency of Low-energy HeNe laser effect in regeneration of Skeletal muscle in mice. Lasers Med Sci. v. 16, p.44-51, 2001.

ANDERS, J. J.; BORKE, R. C.; WOOLERY, S. K.; VAN DE MERWE, W. P. Low power laser irradiation alters the rate of regeneration of the rat facial nerve. Lasers in Surgery and Medicine. v. 13, p.72-75, 1993. 
BEN-DOV, N.; SHEFER, G.; IRINITCHEV, A.; WERNIG, A.; ORON, U.; HALEVY, O. Low-energy laser irradiation affect6s satellite cell proliferation and differentiation in vitro. Biochimica et Biophysica Acta. v.1448, p. 372-380, 1999.

BRUGNERA, A. J.; PINHEIRO, A. L. B. Lasers na Odontologia. São Paulo: Pancast 1998.

BULYAKOVA, N. V.; ZUBKOVA, S. M.; AZAROVA V. S.; VARAKINA, N. I.; MIKHAILIK, L. V. Effect of pulsed laser radiation on regeneration of injuried muscles with different regeneration capacities and state of the Thymus. Doklady Biological Science. v. 382, p. 65-70, 2002.

COLLS, J. Enfoque conceptual de las radiaciones eletromagnéticas. Boletim Del Centro de Documentacion Laser de Meditec. v. 15, p. 1-5, 1988.

COTRAN, R. S.; ROBBINS, S. L. Patologia funcional e estrutural. Rio de Janeiro. Guanabara Koogan, p. 44-47, 2000.

FILHO-FEITAS, G. A.; SILVA, M. F. R.; BELLETI, M. E.; MACHADO, E. R.; SILVA, N. S. Efeito da irradiação de baixa potência Arsianeto de Gálio Alumínio (ASGAAL) de $785 \mathrm{~nm}$ sobre a cicatrização de Lesão Muscular: estudo experimental. Revista UniVap. v. 13, p. 53-60, 2006

FISCHER, B. D.; RENNIE, S.; WARREN, S.; MAGEE, D.; KOH, J. The effects of low power laser therapy muscle haling following acute blunt trauma. J Phys Ther Sci. v. 12, p. 49-55, 2000.

FREITAS, I. G. F.; BARANAUSKAS, V. M. A. Laser effects on osteogenesis. Applied Surface Sci. v. 154, p. 548$54,2000$.

GUIRRO, E.; GUIRRO, R. Fisioterapia Dermato-funcional. 2.ed. São Paulo. Ed. Manole, 2002.

KARU, T.; PYATIBRAT, L.; KALENDO, G. Irradiation with He-Ne laser increase ATP level in cells cultivated in vitro. Journal Photochemistry and Photobiol. v. 27, p. 219-23, 1995.

KARU, T. Low-power Laser Therapy. Biomédical Photonics Handbook. p. 26, 2003.

LAAKSO, L.; RICHARDSON, C.; CRAMOND, T. Factors affecting low level laser therapy. Australian Journal of Physiotherapy. v.39, p. 95-99, 1993.

MATAMALA, F.; VEUTHEY, C.; MOLINA, B.; SILVA, H.; HENRÍQUEZ, J. Efecto del láser infrarrojo de uso clínico sobre el perineuro de nervio isquiático de conejo. Archivos de medicina veterinária. v. 33, p.253-59, 2001

MEDRADO, A. P.; PUGLIESE, L. S.; REIS, S. R. A.; ANDRADE, Z. A. Influence of low level laser therapy on wound healing and its biological action upon myofibroblasts. Lasers in Surgery and Medicine. v. 32, p.239-44, 2003

MINAMOTO, V.B.; GRAZZIANO, C. R.; SALVINI, T. F. Effects of single and periodic trauma contusion on the rat soleus muscle at different stages of regeneration. The Anatomical Record. v. 254, p. 281-87, 1999.

NICOLAU, R. A. Efeito do Laser De Baixa Potencia (As-Ga-Al) em Tecido Ósseo de Rato Submetido à Lesão, Analisando por Histomorfometria Óssea. 2001. Dissertação (Mestrado). Universidade do Vale Paraíba. São Jose dos Campos - SP.

PEREIRA, A. N.; EDUARDO, C. P.; MATSON, E.; MARQUES, M. M. Effect of low-power laser irradiation on cell growth and procollagen synthesis of cultured fibroblasts. Lasers in Surgery and Medicine. v. 31, p.263-67, 2002.

PUGLIESE, L. S.; MEDRADO, A. P.; REIS, S. R. A.; ANDRADE, Z. A. The influence of low-level laser therapy on biomodulation of collagen and elastic fibers. Pesqui Odontol Bras. v.17, 2003.

REDDY, G. K.; BITTEL-STEHNO, L.; ENWEMEKA, C. S. Laser photostimulation of collagen production in healing rabbit achilles tendons. Lasers in Surgery and Medicine. v. 22, p. 281-287, 1998.

SCHINDL, A.; SCHINDL, M.; SCHÖN, H. P.; SCHINDL, L. Low-intensity laser therapy: a review. Journal of Investigative Medicine. v. 48, p. 312-36, 2000. 
SHEFER, G.; BARASH, I.; ORON, U.; HALEVY, O. Low-energy laser irradiation enhances de novo protein synthesis via its effects on translation-regulatory proteins in skeletal muscle myoblasts. Biochimica et Biophysica Acta. v.1593, p. 131-39, 2003.

SHEFER, G.; PARTRIDGE, T. A.; HESLOP, L.; GROSS, J. G.; ORON, U.; HALEVY, O. Low-energy laser irradiation promotes the survival and cell cycle entry of skeletal muscle satellite cells. Journal of Cell Science. $v$. 115, p.1461-469, 2002.

SOTELO, P. R.; SOSA, V. M. R.; MARTíNEZ, R. T.; BARRY, H. G. El láser de helio-neon en la regeneración del nervio ciático seccionado y suturado. Rev. Cubana Cir. v.35, p. 84-89, 1996.

STAINKI, D. R.; RAISER, A. G.; GRAÇA, D. L.; BECKER, C.; FERNANDEZ, G. M. S. The galium arsenide (GaAs) laser radiation in the radial nerve regeneration submitted to secundary surgical repair. Brazilian Journal of Veterinary Research and Animal Science. v. 35, p. 37-40, 1998.

VEÇOSO, M. C. Laser em Fisioterapia. São Paulo. Lovise, 1993.

VICENZO, G. Influência do Laser de baixa energia no processo de consolidação de fraturas de tíbia: estudo experimental em ratos. Revista Brasileira de Ortopedia. São Paulo, v. 36, p 174-78, 2001. 